\title{
DESEMPENHO DE UM TRATOR AGRÍCOLA EQUIPADO COM PNEUS RADIAIS E DIAGONAIS COM TRÊS NÍVEIS DE LASTROS LÍQUIDOS
}

\section{LEONARDO DE A. MONTEIRO ${ }^{1}$, KLÉBER P. LANÇAS ${ }^{2}$, SAULO P. S. GUERRA ${ }^{3}$}

\begin{abstract}
RESUMO: A utilização correta de pneus em tratores, tanto em relação ao seu tipo quanto à calibração de sua pressão interna, e a lastragem ideal para cada condição de carga são fatores que influem significativamente no desempenho do trator. Esta pesquisa teve como objetivo comparar o desempenho de um trator equipado com pneus radiais e com pneus diagonais, para três condições de lastragem líquida $(0 \%, 40 \%$ e $75 \%$ de água), em três condições superficiais de um Nitossolo Vermelho distrófico (superfície firme, preparada e com cobertura vegetal de resto de milho) e em três velocidades teóricas de deslocamento $\left(4 \mathrm{~km} \mathrm{~h}^{-1}, 5 \mathrm{~km} \mathrm{~h}^{-1}\right.$ e $\left.7 \mathrm{~km} \mathrm{~h}^{-1}\right)$, informadas no painel do trator, correspondendo às marchas $\mathrm{B} 1, \mathrm{~B} 2$ e $\mathrm{C} 1$. O melhor desempenho do trator, equipado com pneu diagonal, ocorreu na condição de $75 \%$ de água nos pneus, apresentando maior velocidade de deslocamento, menor patinhagem do trator, menor consumo horário de combustível e gerando maior potência na barra de tração. Com pneus radiais, o melhor desempenho do trator ocorreu na condição de $40 \%$ de água nos pneus, proporcionando maiores velocidades de deslocamento do trator, menores patinhagens, menores consumos, horário e específico de combustível, e maiores potência e rendimento na barra de tração.
\end{abstract}

PALAVRAS-CHAVE: eficiência trativa, máquinas agrícola, ensaio de tratores.

\section{PERFORMANCE OF AN AGRICULTURAL TRACTOR EQUIPPED WITH RADIAL AND BIAS PLY TIRES ON THREE LEVELS OF LIQUID BALLAST}

\begin{abstract}
The correct use of tires, as for its construction type as for internal pressure calibration and the optimal weighting for each load condition are factors that impact significantly on their performance. This study aimed to compare the performance of a tractor equipped with radial tires and bias ply tires in three conditions of liquid ballast $(0 \%, 40 \%$ and $75 \%$ water), three surface conditions of a Dystrophic Red Alfisol (firm surface, tillage surface and surface with corn residues coverage) and three theoretical traveling speeds $\left(4 \mathrm{~km} \mathrm{~h}^{-1}, 5 \mathrm{~km} \mathrm{~h}^{-1}\right.$ and $\left.7 \mathrm{~km} \mathrm{~h}^{-1}\right)$, as indicated at the tractor display, related to the gear boxes B1, B2 and C1. The best tractor's performance, equipped with bias ply tire happened at $75 \%$ water in the tires and it had provide a higher traveling speed, lower slippage, lower fuel consumption per hour and higher drawbar pull power. The radial tires with the best performance happened at $40 \%$ water in tires and it has provided a higher traveling speed, lower slippage, lower fuel consumption per hour, lower specific fuel consumption and higher drawbar pull power bar.
\end{abstract}

KEYWORDS: trative efficiency, agricultural machinery, tractors test.

\footnotetext{
${ }^{1}$ Licenciado em Ciências Agrícolas, Prof. Assistente, Departamento de Engenharia Agrícola, UFC, Fortaleza - CE, aiveca@ufc.br.

${ }^{2}$ Eng $^{\mathrm{o}}$ Mecânico, Prof. Titular, Departamento de Engenharia Rural, UNESP, Botucatu - SP.

${ }^{3}$ Eng $^{\mathrm{o}}$ Florestal, Prof. Assistente Doutor, Departamento de Gestão e Tecnologia, UNESP, Botucatu - SP.

Recebido pelo Conselho Editorial em: 17-8-2009

Aprovado pelo Conselho Editorial em: 19-3-2011
} 


\section{INTRODUÇÃO}

Os rodados pneumáticos de um trator agrícola possuem diversas funções importantes, tais como: garantir o equilíbrio, o deslocamento, o direcionamento, o desempenho operacional e o amortecimento entre as irregularidades do solo e o trator. Os resultados de desempenho operacional do trator são influenciados pelo tipo de construção, pela pressão de inflação, pela carga aplicada, tipo de dispositivo de tração e desgaste dos rodados pneumáticos.

Este trabalho foi realizado com o objetivo de comparar o desempenho de um trator equipado tanto com pneus radiais como com pneus diagonais, em três condições de lastragem líquida do pneu ( $0 \%$ de água, $40 \%$ de água e $75 \%$ de água), em três condições de superfície do solo (firme, mobilizado e com cobertura de restos da cultura de milho) e em três condições de deslocamento, distinguidas pelas seguintes marchas do trator, B1, B2 e C1, com velocidades teóricas, obtidas no painel do trator de $4 ; 5$ e $7 \mathrm{~km} \mathrm{~h}^{-1}$, respectivamente.

A capacidade de tração e o fornecimento de potência suficiente para desempenhar a maioria das operações agrícolas dependem, em parte, do tipo de dispositivo de tração. Nos casos em que esses dispositivos são pneumáticos, o tamanho, a pressão de inflação, a carga aplicada sobre o eixo motriz, a transferência de peso, entre outros, interferem na capacidade de tração do trator (ZOZ \& GRISSO, 2003).

De acordo com BARBOSA (2005), o conjunto pneumático de um trator é um dos seus mais importantes componentes, pois tem a função de obter equilíbrio, deslocamento, direcionamento e esforço tratório.

As condições da superfície do solo afetam também o consumo de combustível do trator. Ao avaliar o consumo de combustível e a capacidade de campo operacional na semeadura de aveia, em três manejos do solo (plantio direto, plantio convencional e escarificação), MAZETTO et al. (2004) concluíram que o consumo horário de combustível e a patinhagem do trator foram maiores onde a operação de semeadura foi realizada em sistema convencional e com escarificação, apresentando maiores exigências trativas, uma vez que nestes manejos houve maior mobilização do solo quando comparado ao sistema de plantio direto.

Avaliando as condições da superfície do solo, GABRIEL FILHO et al. (2010) concluíram que esta interferiu na capacidade do trator em desenvolver a tração, pois a maioria dos parâmetros relacionados com o desempenho apresentou variações estatisticamente significativas ao longo dos ensaios.

NAGAOKA et al. (2002), ao comparar o consumo de combustível de um trator em diferentes tipos de preparo do solo, concluíram que o maior consumo de combustível do trator se deu quando se utilizou o método convencional (aração e gradagem) em relação à área sob o sistema de plantio direto.

SERRANO (2008), ao estudar a utilização de elevadas pressões de inflação dos pneus, concluiu que houve redução da ordem de 3 a 5\% na capacidade de trabalho e aumento significativo, entre 10 e $25 \%$, do consumo de combustível por hectare, mesmo em condições de boa aderência dos pneus, refletidas no intervalo de 7 a $15 \%$ de patinhagem.

$\mathrm{Na}$ avaliação do desempenho operacional de um trator agrícola, em área com diferentes tipos de cobertura vegetal, GABRIEL FILHO et al. (2004) concluíram que a maior quantidade de matéria seca na superfície do solo tende a aumentar a patinhagem e, com isso, diminuir a eficiência de tração.

Relacionando o consumo específico de combustível para cada equipamento, SALVADOR et al. (2009) concluíram que as operações de preparo do solo, tais com arado, grade aradora e escarificador, proporcionaram melhor conversão energética quando utilizados antes da subsolagem, pois os menores valores de consumo específico de combustível significam a otimização do 
desempenho do motor, da eficiência trativa e da adequação do equipamento à fonte de potência, de forma simultânea.

LOPES et al. (2005) compararam o desempenho de um trator agrícola 4x2 TDA de $89 \mathrm{~kW}$ (121 cv) em função do tipo de pneus (radial, diagonal e de baixa pressão), da condição de lastragem (com e sem água nos pneus) e para quatro velocidades $\left(\mathrm{M}_{1}=1,8 \mathrm{~km} \mathrm{~h}^{-1}, \mathrm{M}_{2}=\right.$ $3,1 \mathrm{~km} \mathrm{~h}^{-1}, \mathrm{M}_{3}=4,5 \mathrm{~km} \mathrm{~h}^{-1} \mathrm{e}_{4}=5,0 \mathrm{~km} \mathrm{~h}^{-1}$ ). Os resultados obtidos por esses pesquisadores evidenciaram as vantagens para as situações em que o trator estava equipado com pneus radiais.

Segundo SCHLOSSER et al. (2004), na condição de solo mobilizado, as menores patinhagens do trator ocorreram nos tratamentos em que este apresentava menor peso nas rodas dianteiras e maiores raios estáticos dos pneus, sendo que o mínimo consumo de combustível foi obtido quando a patinhagem estava entre 10 e $15 \%$.

\section{MATERIAL E MÉTODOS}

O experimento foi conduzido na Fazenda Experimental Lageado, pertencente à Faculdade de Ciências Agronômicas - FCA, Universidade Estadual Paulista - UNESP, Câmpus de Botucatu, Estado de São Paulo, no NEMPA - Núcleo de Ensaios de Máquinas e Pneus Agroflorestais, do Departamento de Engenharia Rural, em três pistas de campo, sendo o comprimento de cada uma de $400 \mathrm{~m}$, e largura, de $20 \mathrm{~m}$, totalizando $24.000 \mathrm{~m}^{2}$ de área. As pistas apresentavam declividade de $0,3 \%$ no sentido do comprimento e niveladas na largura. As coordenadas geográficas da área experimental (ponto central), onde estão às pistas, são: $22^{\circ} 51^{\prime} \mathrm{S}, 48^{\circ} 25^{\prime} \mathrm{W}$ e altitude de $770 \mathrm{~m}$. $\mathrm{O}$ solo da área experimental foi classificado por CARVALHO et al. (1983) como Terra Rocha Estruturada, sendo adaptado à classificação da EMBRAPA (1999), como Nitossolo Vermelho distroférrico com relevo plano e textura argilosa.

A mobilização do solo desta área, a semeadura do milho e a cobertura vegetal com os resíduos da colheita da cultura do milho foram realizadas conforme descrito por JESUÍNO (2007).

Os trabalhos foram realizados com um trator John Deere 6600 de $88 \mathrm{~kW}$ (121 cv) de potência no motor, a 2.100 rotações por minuto, e com a tração dianteira auxiliar ligada. Foram selecionadas as marchas B1, B2 e C1, que correspondem às velocidades teóricas, sem carga, de $4 ; 5$ e $7 \mathrm{~km} \mathrm{~h}^{-1}$, respectivamente, conforme consta no painel do trator. Nas Tabelas 1 e 2, mostram-se a massa do trator, a distribuição de peso entre os eixos e a relação entre o peso e a potência do trator equipado com pneus diagonais e com pneus radiais, para as três condições de lastros líquidos.

TABELA 1. Descrição da massa do trator John Deere 6600 equipado com pneus diagonais. Description of the John Deere 6600 tractor mass equipped with bias ply tires.

\begin{tabular}{|c|c|c|c|}
\hline \multicolumn{4}{|c|}{ Condição de Lastro 1 (0\% de água) } \\
\hline Rodado & Peso (kgf) & Distribuição (\%) & Relação Peso/Potência $\left(\mathrm{kg} \mathrm{cv}^{-1}\right)$ \\
\hline Dianteiro & 2.396 & 46 & \multirow{2}{*}{$3_{3}$} \\
\hline Traseiro & 2.887 & 54 & \\
\hline Total & 5.283 & & \\
\hline \multicolumn{4}{|c|}{ Condição de Lastro 2 (40\% de água) } \\
\hline Rodado & Peso (kgf) & Distribuição (\%) & Relação Peso/Potência $\left(\mathrm{kg} \mathrm{cv}^{-1}\right)$ \\
\hline Dianteiro & 2.560 & 47 & \multirow[t]{2}{*}{ s } \\
\hline Traseiro & 2.887 & 53 & \\
\hline Total & 5.447 & & \\
\hline \multicolumn{4}{|c|}{ Condição de Lastro 3 (75\% de água) } \\
\hline Rodado & Peso (kgf) & Distribuição (\%) & Relação Peso/Potência $\left(\mathrm{kg} \mathrm{cv}^{-1}\right)$ \\
\hline Dianteiro & 2.756 & 40 & \multirow{2}{*}{ 3 } \\
\hline Traseiro & 3.967 & 60 & \\
\hline Total & 6.723 & & \\
\hline
\end{tabular}


A pressão de inflação para os pneus radiais foi de $96,5 \mathrm{kPa}(14 \mathrm{psi})$ nos rodados traseiros e $82,7 \mathrm{kPa}$ (12 psi) nos dianteiros, e, para os pneus diagonais, foi de 124,02 $\mathrm{kPa}$ (18 psi) nos rodados dianteiros e de $137,8 \mathrm{kPa}$ (20 psi) nos rodados traseiros, conforme recomendação do fabricante dos pneus. O percentual de lastro líquido foi determinado conforme MONTEIRO \& ARBEX (2009).

Para fornecer a força na barra de tração, foi utilizada a Unidade Móvel de Ensaio na Barra de Tração - UMEB (Figura 1), desenvolvida pelo Núcleo de Ensaio de Máquinas e Pneus Agroflorestais - NEMPA, e citada por MONTEIRO et al. (2007) e GABRIEL FILHO et al. (2008).

Foram realizadas amostragens do teor de água do solo nas três pistas, nas camadas de 0 a $10 \mathrm{~cm}$ e 10 a $20 \mathrm{~cm}$, com 10 repetições, alocadas de forma aleatória.

TABELA 2. Descrição da massa do trator John Deere 6600 equipado com pneus radiais. Description of the John Deere 6600 tractor mass equipped with radial tires.

\begin{tabular}{|c|c|c|c|}
\hline \multicolumn{4}{|c|}{ Condição 1 (0\% de água) } \\
\hline Rodado & Peso (kgf) & Distribuição (\%) & Relação Peso/Pot $\left(\mathrm{kg} \mathrm{cv}^{-1}\right)$ \\
\hline Dianteiro & 1.582 & 44 & \multirow{2}{*}{33,5} \\
\hline Traseiro & 2.471 & 56 & \\
\hline Total & 4.053 & & \\
\hline \multicolumn{4}{|c|}{ Condição 2 (40\% de água) } \\
\hline Rodado & Peso (kgf) & Distribuição (\%) & Relação Peso/Pot $\left(\mathrm{kg} \mathrm{cv}^{-1}\right)$ \\
\hline Dianteiro & 2.466 & 45 & \multirow{2}{*}{45,4} \\
\hline Traseiro & 3.031 & 55 & \\
\hline Total & 5.497 & & \\
\hline \multicolumn{4}{|c|}{ Condição 3 (75 \% de água) } \\
\hline Rodado & Peso (kgf) & Distribuição (\%) & Relação Peso/Pot $\left(\mathrm{kg} \mathrm{cv}^{-1}\right)$ \\
\hline Dianteiro & 2.662 & 42 & \multirow{2}{*}{52,3} \\
\hline Traseiro & 3.671 & 58 & \\
\hline Total & 6.333 & & \\
\hline
\end{tabular}

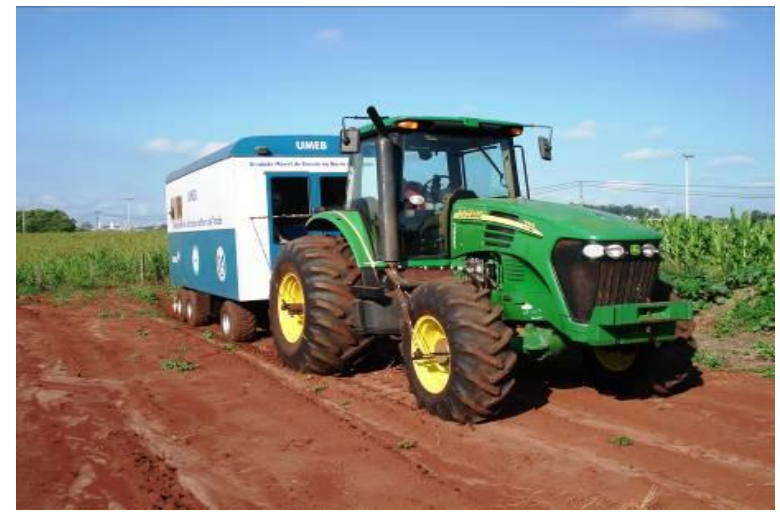

FIGURA 1. Trator acoplado à UMEB - Unidade Móvel de Ensaio na Barra de tração. Tractor attached to DBMU - Draw Bar Mobile Unit.

Para determinar a resistência do solo à penetração, foi utilizada a UMAS - Unidade Móvel de Amostragem de Solo, desenvolvida pelo NEMPA - Núcleo de Ensaio de Máquinas e Pesquisas Agroflorestais. Os valores médios do teor de água e o índice de cone do solo estão apresentados na Tabela 3.

Para a aquisição e o monitoramento dos sinais obtidos pelos sensores instalados nos rodados pneumáticos, na tomada de potência, no sistema de alimentação de combustível e na barra de 
tração, foi instalado, no interior da UMEB, um controlador lógico programável (CLP), com interface homem/máquina incorporada.

TABELA 3. Caracterização do solo: Pista 1 - solo mobilizado; Pista 2 - solo com cobertura vegetal, e Pista 3 - solo firme. Soil Characterization: Track 1 - mobilized soil, Track 2 - soil with vegetal cover and Track 3 - firm soil.

\begin{tabular}{|c|c|c|c|}
\hline Característica & Pista 1 & Pista 2 & Pista 3 \\
\hline Areia $(\%)$ & 42,8 & 42,1 & 41,0 \\
\hline Silte $(\%)$ & 18,9 & 16,9 & 17,0 \\
\hline Argila $(\%)$ & 38,3 & 41,0 & 42,0 \\
\hline Limite de liquidez (\%) & 33,5 & 31,8 & 32,0 \\
\hline Limite de plasticidade $(\%)$ & 25,8 & 26,2 & 25,3 \\
\hline Densidade dos sólidos $\left(\mathrm{g} \mathrm{cm}^{-3}\right)$ & 3,0 & 3,1 & 3,0 \\
\hline Teor de Água kg kg $\mathrm{kg}^{-1} \quad 0-10 \mathrm{~cm}$ & 19,1 & 21,9 & 19,5 \\
\hline $10-20 \mathrm{~cm}$ & 19,8 & 22,0 & 19,8 \\
\hline Índice de cone $(\mathrm{kPa}) \quad 0-15 \mathrm{~cm}$ & 750 & 1.684 & 3.629 \\
\hline Massa de matéria seca $\left(\mathrm{kg} \mathrm{ha}^{-1}\right)$ & - & 10.089 & - \\
\hline
\end{tabular}

Os valores da força na barra de tração foram obtidos através de uma célula de carga marca SODMEX, modelo N400, com sensibilidade de 2,16 mV/V e escala nominal de $100 \mathrm{kN}$. Essa célula foi instalada no cabeçalho da UMEB para permitir um controle da força de tração necessária para o deslocamento da unidade móvel nos ensaios.

A determinação da patinhagem das quatro rodas do trator foi obtida utilizando-se de geradores de pulsos, modelo GIDP-60-U-12V, com uma frequência de 60 pulsos por volta.

Para a medição do consumo horário de combustível, foi utilizado um fluxômetro volumétrico M-III, FLOWMATE, fabricado pela OVAL Corporation do Japão, e distribuído no Brasil pela K\&K do Brasil, modelo LSN41L8-M2, vazão de $1 \mathrm{~mL} \mathrm{pulso}^{-1}$.

Os sinais gerados pelos sensores foram armazenados no coletor de dados (CLP) e, posteriormente, transferidos para um computador para serem manipulados e analisados.

Para medir a temperatura do combustível, foi utilizado um termômetro de platina tipo PT100, instalado no sistema de alimentação do trator, próximo ao medidor de consumo. $\mathrm{O}$ consumo específico de combustível foi determinado considerando a potência exigida, após a passagem em cada uma das parcelas.

O delineamento experimental utilizado foi em faixas (PIMENTEL-GOMES \& GARCIA, 2002), constituído pelas pistas e definidas pelas condições da superfície do solo (superfície mobilizada, superfície com cobertura vegetal e superfície firme).

Em cada pista, foram dispostos os tratamentos em blocos ao acaso, com um arranjo fatorial $2 \times 3 \times 3$, sendo analisado o tipo construtivo do pneu (Radial e Diagonal), as marchas do trator (B1, B2 e C1) e a condição de lastragem líquida do pneu ( $0 \%, 40 \%$ e $75 \%$ de água), com três repetições por faixa, totalizando 162 unidades experimentais. Esses fatores foram arranjados para permitir a avaliação dos efeitos das variáveis individualmente ou em grupos, sendo todos os dados submetidos à análise de variância, aplicando o teste de Tukey, a 5\% de probabilidade, para a comparação das médias.

\section{RESULTADOS E DISCUSSÃO}

Os valores das patinhagens dos rodados do trator, nas três condições de superfície do solo, nas três condições de lastragem líquida e para os dois tipos de pneu, estão apresentados na Tabela 4. 
Na pista com superfície mobilizada, a patinagem foi maior, atingindo níveis intermediários na pista com cobertura vegetal, e os menores valores de patinhagem ocorreram na pista com superfície firme. Esses resultados mostram que as condições da superfície do solo podem alterar significativamente o esforço tratório, pois a tração está diretamente relacionada à patinhagem do trator. Diferentes condições da superfície do solo causam diferentes condições de patinhagem dos rodados do trator, confirmando os resultados relatados por MAZETTO et al. (2004) e GABRIEL FILHO et al. (2004).

TABELA 4. Valores médios da patinhagem do rodado do trator em função do tipo construtivo do pneu para a interação pneu x lastro, na pista com superfície mobilizada (1), pista com cobertura vegetal (2) e pista de solo firme (3). Average slip of the tractor wheels according to the constructive tire type, for tire $\mathbf{x}$ ballast interaction, on mobilized track (1), track with vegetal cover (2) and firm soil track (3).

\begin{tabular}{|c|c|c|c|}
\hline & \multicolumn{3}{|c|}{ Pista com Superfície Mobilizada (1) } \\
\hline & \multicolumn{3}{|c|}{ Água $(\%)$} \\
\hline & 0 & 40 & 75 \\
\hline Pneu Diagonal & $28,8 \mathrm{aA}^{*}$ & $21,4 \mathrm{aB}$ & $12,2 \mathrm{aC}$ \\
\hline \multirow[t]{4}{*}{ Pneu Radial } & $34,7 \mathrm{aA}$ & $13,3 \mathrm{bB}$ & $16,5 \mathrm{aB}$ \\
\hline & \multicolumn{3}{|c|}{ Pista com Cobertura Vegetal (2) } \\
\hline & \multicolumn{3}{|c|}{ Água $(\%)$} \\
\hline & 0 & 40 & 75 \\
\hline Pneu Diagonal & $12,1 \mathrm{aA}$ & $11,3 \mathrm{aA}$ & $9,1 \mathrm{aB}$ \\
\hline \multirow[t]{4}{*}{ Pneu Radial } & $15,9 \mathrm{bA}$ & $8,3 \mathrm{bB}$ & $9,8 \mathrm{aB}$ \\
\hline & \multicolumn{3}{|c|}{ Pista de Solo Firme (3) } \\
\hline & \multicolumn{3}{|c|}{ Água $(\%)$} \\
\hline & 0 & 40 & 75 \\
\hline Pneu Diagonal & $3,3 \mathrm{aAC}$ & $8,4 \mathrm{aB}$ & $3,2 \mathrm{aC}$ \\
\hline Pneu Radial & $7,7 \mathrm{bA}$ & $5,6 \mathrm{bB}$ & $5,3 \mathrm{bB}$ \\
\hline
\end{tabular}

* Médias seguidas de mesmas letras, maiúscula na coluna e minúsculas na linha, não diferem entre si, pelo teste de Tukey-Kramer $(\mathrm{p}<5 \%)$.

O consumo horário de combustível para gerar a potência na barra de tração para tracionar a UMEB está descrito na Tabela 5, que mostra diferença significativa para a interação pneu e lastro, apenas para a condição de $40 \%$ de água e na pista com superfície firme, com valores maiores para o pneu diagonal.

O consumo horário de combustível foi maior na pista com superfície mobilizada e semelhante entre as pistas com cobertura vegetal e superfície firme, concordando com os resultados de SALVADOR et al. (2009) e GABRIEL FILHO et al. (2004). A mobilização do solo fez com que o trator consumisse mais combustível para manter a rotação do motor nos níveis desejados para exercer a tração de $25 \mathrm{kN}$, aproximadamente. NAGAOKA et al. (2002) também observaram maior consumo de combustível do trator em área com solo preparado pelo método convencional (aração e gradagem), em relação à área sob o sistema de plantio direto.

Em relação às condições estudadas de variação do lastro líquido no pneu, não houve diferença estatisticamente significativa entre os tipos construtivos de pneus (diagonal e radial); porém, para a pista com superfície mobilizada (Tabela 6), os menores valores de potência na barra de tração, com diferença significativa, foram obtidos para $0 \%$ de lastro, sendo que as outras condições (40 e 75\%) não diferiram entre si. 
TABELA 5. Valores médios do consumo horário de combustível, $\mathrm{Ch}\left(\mathrm{L} \mathrm{h}^{-1}\right)$ em função do tipo construtivo do pneu, para a interação pneu x lastro, na pista com superfície mobilizada (1), pista com cobertura vegetal (2) e pista de solo firme (3). Average fuel consumption, $\mathrm{Ch}\left(\mathrm{L} . h^{-1}\right)$ in function of constructive tire type, for tire $\mathrm{x}$ ballast interaction on mobilized track (1), track with vegetal cover (2) and firm soil track (3).

\begin{tabular}{|c|c|c|c|}
\hline & \multicolumn{3}{|c|}{ Pista com Superfície Mobilizada (1) } \\
\hline & \multicolumn{3}{|c|}{ Água $(\%)$} \\
\hline & 0 & 40 & 75 \\
\hline Pneu Diagonal & $17,7 \mathrm{aA}^{*}$ & $17,6 \mathrm{aA}$ & $16,7 \mathrm{aA}$ \\
\hline \multirow[t]{4}{*}{ Pneu Radial } & $17,8 \mathrm{aA}$ & $16,6 \mathrm{aB}$ & $17,5 \mathrm{aA}$ \\
\hline & \multicolumn{3}{|c|}{ Pista com Cobertura Vegetal (2) } \\
\hline & \multicolumn{3}{|c|}{ Água $(\%)$} \\
\hline & 0 & 40 & 75 \\
\hline Pneu Diagonal & $16,9 \mathrm{aA}$ & $16,8 \mathrm{aA}$ & $15,9 \mathrm{aA}$ \\
\hline \multirow[t]{4}{*}{ Pneu Radial } & $16,5 \mathrm{aA}$ & $15,9 \mathrm{aA}$ & $16,6 \mathrm{aA}$ \\
\hline & \multicolumn{3}{|c|}{ Pista de Solo Firme (3) } \\
\hline & \multicolumn{3}{|c|}{ Água (\%) } \\
\hline & 0 & 40 & 75 \\
\hline Pneu Diagonal & $16,6 \mathrm{aA}$ & $16,7 \mathrm{aA}$ & $15,8 \mathrm{aA}$ \\
\hline Pneu Radial & $16,2 \mathrm{aAB}$ & $15,3 \mathrm{bB}$ & $16,4 \mathrm{aA}$ \\
\hline
\end{tabular}

* Médias seguidas de letras iguais, minúsculas na coluna e maiúscula na linha, não diferem entre si, pelo teste de Tukey-Kramer $(\mathrm{p}<5 \%)$.

TABELA 6. Valores médios da potência na barra de tração $\mathrm{Pb}(\mathrm{kW})$ do trator em função do tipo construtivo do pneu, para a interação pneu $\mathrm{x}$ lastro, na pista com superfície mobilizada (1), pista com cobertura vegetal (2)e pista de solo firme (3). Average tractor draw bar power $\mathrm{Pb}(\mathrm{kW})$ in function of constructive tire type, for tire $\mathrm{x}$ ballast interaction on mobilized track (1), track with vegetal cover (2) and firm soil track (3).

\begin{tabular}{|c|c|c|c|}
\hline & \multicolumn{3}{|c|}{ Pista com Superfície Mobilizada (1) } \\
\hline & \multicolumn{3}{|c|}{ Água $(\%)$} \\
\hline & 0 & 40 & 75 \\
\hline Pneu Diagonal & $27,5 \mathrm{aA}^{*}$ & $30,1 \mathrm{aAB}$ & $32,8 \mathrm{aB}$ \\
\hline \multirow[t]{4}{*}{ Pneu Radial } & $23,7 \mathrm{aA}$ & $33,1 \mathrm{aB}$ & $29,2 \mathrm{aB}$ \\
\hline & \multicolumn{3}{|c|}{ Pista com Cobertura Vegetal (2) } \\
\hline & \multicolumn{3}{|c|}{ Água $(\%)$} \\
\hline & 0 & 40 & 75 \\
\hline Pneu Diagonal & 33,8 aA & $33,9 \mathrm{aA}$ & $33,7 \mathrm{aA}$ \\
\hline \multirow[t]{4}{*}{ Pneu Radial } & $31,2 \mathrm{aA}$ & $34,4 \mathrm{aA}$ & $33,4 \mathrm{aA}$ \\
\hline & \multicolumn{3}{|c|}{ Pista de Solo Firme (3) } \\
\hline & \multicolumn{3}{|c|}{ Água $(\%)$} \\
\hline & 0 & 40 & 75 \\
\hline Pneu Diagonal & $35,4 \mathrm{aA}$ & $35,6 \mathrm{aA}$ & 34,6 aA \\
\hline Pneu Radial & $35,6 \mathrm{aA}$ & $35,4 \mathrm{aA}$ & $37,9 \mathrm{aA}$ \\
\hline
\end{tabular}


A quantidade de combustível para gerar a potência necessária na barra de tração, para tracionar a UMEB, entre as três condições de superfícies, foi diferente, sendo que os maiores valores de consumo específico de combustível ocorreram na pista com superfície mobilizada, seguida da pista com cobertura vegetal e pela pista com superfície firme, conforme mostram os dados da Tabela 7.

TABELA 7. Valores médios do consumo específico de combustível Cesp ( $\mathrm{g} \mathrm{kW} \mathrm{h}^{-1}$ ), do trator, em função do tipo construtivo do pneu, para a interação pneu x lastro, na pista com superfície mobilizada (1), pista com cobertura vegetal (2) e pista de solo firme (3). Average of specific fuel consumption, $\operatorname{Cesp}\left(\mathrm{g} . \mathrm{kW} \cdot \mathrm{h}^{-1}\right)$, in function of constructive tire type, for tire $x$ ballast interaction on mobilized track (1), track with vegetal cover (2) and firm soil track (3).

\begin{tabular}{|c|c|c|c|}
\hline & \multicolumn{3}{|c|}{ Pista com Superfície Mobilizada (1) } \\
\hline & \multicolumn{3}{|c|}{ Água $(\%)$} \\
\hline & 0 & 40 & 75 \\
\hline Pneu Diagonal & $539,1 \mathrm{aA}^{*}$ & $492,6 \mathrm{aA}$ & $428,7 \mathrm{aB}$ \\
\hline \multirow[t]{4}{*}{ Pneu Radial } & $642,0 \mathrm{bA}$ & $419,2 \mathrm{bB}$ & $511,4 \mathrm{bC}$ \\
\hline & \multicolumn{3}{|c|}{ Pista com Cobertura Vegetal (2) } \\
\hline & \multicolumn{3}{|c|}{ Água $(\%)$} \\
\hline & 0 & 40 & 75 \\
\hline Pneu Diagonal & $421,3 \mathrm{aA}$ & $416,1 \mathrm{aA}$ & $396,5 \mathrm{aA}$ \\
\hline \multirow[t]{4}{*}{ Pneu Radial } & $447,3 \mathrm{aA}$ & $386,6 \mathrm{aB}$ & $422,2 \mathrm{a} A B$ \\
\hline & \multicolumn{3}{|c|}{ Pista de Solo Firme (3) } \\
\hline & \multicolumn{3}{|c|}{ Água $(\%)$} \\
\hline & 0 & 40 & 75 \\
\hline Pneu Diagonal & $394,9 \mathrm{aA}$ & $394,9 \mathrm{aA}$ & $381,2 \mathrm{aA}$ \\
\hline Pneu Radial & $393,9 \mathrm{aA}$ & $361,6 \mathrm{bB}$ & $365,1 \mathrm{bB}$ \\
\hline
\end{tabular}

A mobilização do solo diminuiu a capacidade do trator em desenvolver a tração, pois o solo desagregado não ofereceu a mesma reação quando comparado com o mesmo tipo de solo em que não houve a desagregação das partículas. Essa situação requer mais energia do trator para a tração e, com isso, maior consumo específico de combustível, para manter a velocidade do trator, conforme também foi relatado por NAGAOKA et al. (2002).

Em relação às condições estudadas de lastro líquido no pneu, não houve diferença estatisticamente significativa entre os tipos de pneu (diagonal e radial); porém, para a pista com superfície mobilizada e com pneu radial, os menores valores de rendimento na barra de tração, com diferença estatisticamente significativa, foram obtidos para $0 \%$ de água, sendo que as outras condições (40 e 75\%) não diferiram entre si, conforme mostra a Tabela 8. 
TABELA 8. Valores médios do rendimento na barra de tração do trator Rbt (\%), em função do tipo construtivo do pneu, para a interação pneu x lastro, na pista com superfície mobilizada (1), pista com cobertura vegetal (2) e pista de solo firme (3). Average tractor draw bar income $\mathrm{Rbt}(\%)$ in function of constructive tire type, for tire $\mathrm{x}$ ballast interaction on mobilized track (1), track with vegetal cover (2) and firm soil track (3).

\begin{tabular}{|c|c|c|c|}
\hline & \multicolumn{3}{|c|}{ Pista com Superfície Mobilizada (1) } \\
\hline & \multicolumn{3}{|c|}{ Água $(\%)$} \\
\hline & 0 & 40 & 75 \\
\hline Pneu Diagonal & $31,2 \mathrm{aA}^{*}$ & $34,2 \mathrm{aAB}$ & $37,3 \mathrm{aAB}$ \\
\hline \multirow[t]{4}{*}{ Pneu Radial } & $26,9 \mathrm{aA}$ & $37,6 \mathrm{aB}$ & $33,2 \mathrm{aB}$ \\
\hline & \multicolumn{3}{|c|}{ Pista com Cobertura Vegetal (2) } \\
\hline & \multicolumn{3}{|c|}{ Água $(\%)$} \\
\hline & 0 & 40 & 75 \\
\hline Pneu Diagonal & $38,4 \mathrm{aA}$ & $38,6 \mathrm{aA}$ & $38,3 \mathrm{aA}$ \\
\hline \multirow[t]{4}{*}{ Pneu Radial } & $35,5 \mathrm{aA}$ & $39,1 \mathrm{aA}$ & $38,0 \mathrm{aA}$ \\
\hline & \multicolumn{3}{|c|}{ Pista de Solo Firme (3) } \\
\hline & \multicolumn{3}{|c|}{ Água $(\%)$} \\
\hline & 0 & 40 & 75 \\
\hline Pneu Diagonal & $40,3 \mathrm{aA}$ & $40,4 \mathrm{aA}$ & $39,3 \mathrm{aA}$ \\
\hline Pneu Radial & 39,3 aA & $40,2 \mathrm{aA}$ & $43,1 \mathrm{aA}$ \\
\hline
\end{tabular}

* Médias seguidas de letras iguais, minúsculas na coluna e maiúscula na linha, não diferem entre si, pelo teste de Tukey-Kramer $(\mathrm{p}<5 \%)$.

\section{CONCLUSÕES}

Os menores valores de patinhagem e consumo horário de combustível foram obtidos para a lastragem com $40 \%$ de água, quando o trator estava equipado com pneus radiais. Os tratamentos com solo mobilizado apresentaram os maiores valores de patinhagem e de consumo horário de combustível, mostrando que esta condição superficial do solo foi responsável pelo menor desempenho do trator. O melhor desempenho do trator, quando equipado com pneu diagonal, ocorreu com a lastragem líquida de $75 \%$ de água nos pneus. As pistas com superfície firme e com cobertura vegetal apresentaram resultados de desempenho operacional e energético semelhantes na maioria das condições estudadas.

\section{REFERÊNCIAS}

BARBOSA, J.A.; VIEIRA, L.B.; DIAS, G.P.; DIAS JÚNIOR, M.S. Desempenho operacional de um trator agrícola equipado alternadamente com pneus radiais e diagonais. Engenharia Agrícola, Jaboticabal, v.25, n.2, p.474-480, 2005. Online.

CARVALHO, W.A.; ESPÍNDOLA, C.R.; PACCOLA, A.A. Levantamento de solos da Fazenda Lageado - Estação Experimental "Presidente Médici". Boletim Científico da Faculdade de Ciências Agronômicas da UNESP, Botucatu, n.1, p.1-85, 1983.

EMBRAPA. EMPRESA BRASILEIRA DE PESQUISAS AGROPECUÁRIAS. Centro Nacional de Pesquisa de Solos. Sistema brasileiro de classificação de solos. Rio de Janeiro: Embrapa, 1999. $412 \mathrm{p}$.

GABRIEL FILHO, A.; SILVA, S.L.; MODOLO, A.J.; SILVEIRA, J.C.M. Desempenho de um trator operando em solo com diferentes tipos de cobertura vegetal. Engenharia Agrícola, Jaboticabal, v.24, n.3, p.781-789, 2004. Online. 
GABRIEL FILHO, A.; LANÇAS, K.P.; GUERRA, S.P.; PAULA, C.A.; MONTEIRO, L.A. UMEB - Unidade móvel para ensaio da barra de tração. Engenharia Agrícola, Jaboticabal, v.28, n.4, p.782789, 2008. Online.

GABRIEL FILHO, A.; LANÇAS, K.P.; LEITE, F.; ACOSTA, J.J.B.; JESUINO, P.R. Desempenho do trator agrícola em três superfícies de solo e quatro velocidades de deslocamento. Revista Brasileira de Engenharia Agrícola e Ambiental, Campina Grande, v.14, n.3, p.333-339, 2010.

JESUÍNO, P.R. Desempenho de um trator agrícola em função do desgaste das garras dos pneus e das condições superficiais do solo. 2007. 64 f. Dissertação (Mestrado em Energia na Agricultura) Faculdade de Ciências Agronômicas, Universidade Estadual Paulista, Botucatu, 2007.

LOPES, A.; LANÇAS, K.P.; SILVA, R.P.; FURLANI, C.E.A.; NAGAOKA, A.K. ; REIS, G.N. Desempenho de um trator em função do tipo de pneu, da lastragem e da velocidade de trabalho. Ciência Rural, Santa Maria, v.35, n.2, p.366-370, 2005. Online.

MAZETTO, F.R.; LANÇAS, K.P.; NAGAOKA, A.K.; CASTRO NETO, P.; GUERRA, S.P.S. Avaliação do contato pneu-solo em três modelos de pneus agrícolas. Engenharia Agrícola, Sorocaba, v.24, n.3, p.750-757, 2004. Ojline.

MONTEIRO, L.A.; ARBEX , P.R. Operação com tratores agrícolas. Botucatu: Ed. dos Autores, 2009.76 p.

MONTEIRO, L.A.; LANÇAS, K.P.; GABRIEL FILHO, A.; GUERRA, S.P.S.; TOSIN, C.A.; PAULA, C.A. Construção e Avaliação da Unidade Móvel para Ensaio na Barra de Tração. In: CONGRESSO BRASILEIRO DE ENGENHARIA AGRÍCOLA, 36., 2007, Bonito. Anais... Bonito: SBEA, 2007. 1 CD-ROM.

NAGAOKA, A.K.; NOMURA, R.H.C.; BRÖRING, N.; KITANO, N.; JASPER, S.P. Avaliação do consumo de combustível, patinhagem e capacidade de campo operacional na operação de semeadura da cultura de aveia-preta (Avena strigosa) em três sistemas de manejo do solo. In: CONGRESSO BRASILEIRO DE ENGENHARIA AGRÍCOLA, 31., 2002, Salvador. Anais... Salvador: SBEA/UFBA, 2002. 1 CD-ROM.

PIMENTEL-GOMES, F.; GARCIA, C.H. Estatística aplicada a experimentos agronômicos e florestais: Exposição com exemplos e orientações para uso de aplicativos. Piracicaba: Fealq, 2002. $309 \mathrm{p}$.

SALVADOR, N.; MION, R.L.; BENEZ, S.H. Consumo de combustível em diferentes sistemas de preparo periódico realizados antes e depois da operação de subsolagem. Ciência Agrotécnica, v.33, n.3, p. 870-874, 2009.Online.

SERRANO, J.M.P.R. Pressão de insuflagem dos pneus no desempenho do conjunto trator-grade de discos. Pesquisa Agropecuária Brasileira, v.43, n.2, p.227-233, 2008. Online.

SCHLOSSER, J.F.; LINARES, P.; MARQUEZ, L. Influence of the kinematics advance on the traction efficiency of the front wheel assist tractor. Ciência Rural, Santa Maria, v.34, n.6, p.1.801$1.805,2004$. Online.

ZOZ, F.; GRISSO, R.D. Traction and tractor performance. St Joseph: ASAE. 2003. 46 p. 